PREIMPLANTATION GENETIC DIAGNOSIS OF GENDER SELECTION IN THE

\title{
4 UNITED STATES
}

5

6

7
Author(s): Colls P (Colls, P.) $)^{1}$, Silver L (Silver, L. $)^{\underline{2}}$, Olivera G (Olivera, G. $)^{\underline{3}}$, Weier J (Weier, J. $)^{\frac{3}{2}}$, Escudero T (Escudero, T. $)^{\frac{3}{1}}$, Goodall N (Goodall, N.) $)^{\frac{1}{1}}$ Tomkin G (Tomkin, G. $)^{\underline{1}}$, Munne S (Munne, S.) ${ }^{1}$

1. Reprogenetics LLC, Livingston, NJ 07039 USA

2. Princeton Univ, Dept Mol Biol, Princeton, NJ 08544 USA

3. Reprogenetics LLC, San Francisco, CA 94080 USA
This work was supported in parts by a grant from the Director, office of Energy Research, Office of Health and Environmental Research, U.S. Department of Energy, under contract DE-ACO2-05CH11231. 


\section{ABSTRACT}

32 Preimplantation genetic diagnosis (PGD) of gender selection for non medical reasons has been

33 considered an unethical procedure by several authors and agencies in the Western society on the

34 basis of disrupting the sex ratio, being discriminatory againsts women and disposal of normal

35 embryos of the non desired gender. In this study, the analysis of a large series of PGD

36 procedures for gender selection from a wide geographical area in the United States, shows that in

37 general there is no deviation in preference towards any specific gender except for a preference of

38 males in some ethnic populations of Chinese, Indian and Middle Eastern origin that represent a

39 small percentage of the US population. In cases where only normal embryos of the non-desired

40 gender are available, $45.5 \%$ of the couples elect to cancel the transfer, while $54.5 \%$ of them are

41 open to have transferred embryos of the non-desired gender, this fact being strongly linked to

42 cultural and ethnical background of the parents. In addition this study adds some evidence to the

43 proposition that in couples with previous children of a given gender there is no biological

44 predisposition towards producing embryos of that same gender. Based on these facts, it seems

45 that objections to gender selection formulated by ethics committees and scientific societies are 46 not well-founded.

\section{SUMMARY}

51 Preimplantation genetic diagnosis of gender selection for non medical reason is considered

52 unethical by scientific societies and ethics committees claiming that the sex ratio of the

53 population can be disrupted, that it is discriminatory against women and regarding the fate of 
54 normal embryos of the undesired gender. Some studies show there is a biass towards males in the

55 general population suggesting that may be originated by some biological processes. This study of

56 a large series of PGD cases for gender selection shows that there is no deviation towards male or

57 females in the gender preferences of patients from an ethnically diverse western society like the

58 United States, with the exception of some ethic populations of Chinese, Indian and Middle

59 Eastern origin where a biass towards males has been observed. Since these populations represent

60 an extremelly small percentage of the population in the United States, the general sex ratio

61 cannot be disrupted. This study also shows that in couples with previous children of a given

62 gender there is no predisposition to conceive embryos of that gender and that in general there is

63 no biass towards males in the gender of embryos, suggesting that the biass towards males in the

64 general population is not reflected in the early stages of development. Based on these facts, it 65 seems that objections to gender selection formulated by ethics committees and scientific societies 66 are not well-founded.

67

68 KEY WORDS

69 Preimplantation Genetic Diagnosis, gender selection, FISH, ethics committees

\section{INTRODUCTION}

74 Preimplantation genetic diagnosis (PGD) analysis is being used to improve ART outcome

75 (Gianaroli et al., 1999; Munné et al., 1999; Munné et al., 2003), for couples with idiopathic 76 recurrent pregnancy loss (Munné et al., 2005; Garrisi et al., 2008), carriers of structural 
77 chromosome abnormalities (Otani et al., 2006; Escudero et al., 2008), and gene defects (Harper

78 et al., 2002; Fiorentino et al., 2003).

79 Since aneuploidy of sex chromosomes in human embryos can lead to offspring with Turner's

80 Syndrome, Klinefelter's Syndrome, and other abnormalities compatible with post-natal viability,

81 probes for chromosomes $\mathrm{X}$ and $\mathrm{Y}$ have been included in most PGD protocols using FISH, with

82 occasional exceptions for indications of structural chromosome abnormalities. Currently, most

83 X-linked genetic defects are diagnosed by PGD using molecular methods that allow specific

84 identification of the mutation (Amor and Cameron, 2008). However, in the recent past,

85 karyotype-based gender determination was used to prevent X-linked disorders like hemophilia.

86 For those syndromes with no clear genetic association and an increased male incidence like

87 autism, FISH is still used for gender determination.

88 While sex selection of embryos for medical indications is well accepted (Ethics Committee of

89 the American Society for Reproductive Medicine, ASRM, 2001), controversy arises regarding

90 sex selection for family balance or gender preference purposes, which many people believe to be

91 unethical. Two main reasons are cited: one is the risk of biasing sex ratios in the population at-

92 large and/or gender discrimination, and the other that chromosomally normal embryos are being

93 discarded. Considering gender bias, many believe gender selection is discriminatory and sexist;

94 they argue that it would lead to a severe distortion of the sex ratio based on the assumption that a

95 large proportion of couples would select male offspring (American College of Obstetricians and

96 Gynecologists, ACOG, 2007; Robertson 2002; Human Fertilization and Embryology Authority,

97 2003; International Federation of Gynecology and Obstetrics, FIGO, 2006).

98 However, several studies have demonstrated that although in some countries like China and India

99 the sex ratio can be distorted in favor of males, in Western societies there is no evidence of such 
100 effect and that gender preferences are usually the result of a desire to have a family with children

101 of both genders (family balancing) (Dahl et al., 2003; Heyd 2003; Jain et al., 2005; Dahl et al.,

102 2006a; Dahl et al., 2006b; Fejes et al., 2006). All but one of these studies have been carried out

103 through opinion surveys, questionnaires, or analysis of newborn data. The one exception is based

104 on results from a series of 92 PGD assays for gender selection in the New York area (Gleicher

105 and Barad, 2007). Overall, the data suggest a strong sex selection towards males remains

106 confined in that area to some minority ethnic groups of Chinese, Middle Eastern/Muslim and

107 Indian origin and that no bias or a slight preference for females is observed among couples of

108 Western origin.

109 The second controversial issue regarding gender determination is the disposal of chromosomally

110 normal embryos because they are the unwanted gender. As a result of this concern, pre-

111 fertilization techniques like sperm sorting are favored over post-fertilization techniques like PGD

112 (Robertson 2002; ACOG 2007). No studies have been done to determine the proportion of

113 couples seeking PGD for gender determination who are willing (non-absolute preference) or not

114 willing (absolute preference) to transfer embryos from the unwanted gender when these are the

115 only ones available .

116 The policy of our laboratory has been that we offer PGD for all indications but not specifically

117 for gender determination. However, since FISH procedures usually involve the analysis of $\mathrm{X}$ and

118 Y chromosomes, and regulating agencies (i.e. New York State Department of Health) request the

119 disclosure of all genetic information obtained, we know the test is being used by some doctors

120 for gender determination as well as aneuploidy. 
121 Before deciding whether to modify our policy or not, we chose to request further information

122 from those IVF centers sending us PGD samples so we could uncover any bias in gender

123 prediction.

124 A second purpose of this study was to evaluate the popular belief that families with all same-

125 gender children are predisposed to produce either more girls or more boys than the population at-

126 large. Previous studies of very large birth cohorts have not supported this belief (Maconochie

127 and Roman, 1997). But no published reports have looked directly for gender bias at the stage of

128 fertilization and embryo production within the two subpopulations of couples who have children

129 all of one gender or the other. Here we present the confirmed data of 276 PGD cycles involving

130 gender selection from 53 different IVF centers throughout the United States.

132 MATERIALS AND METHODS

\section{Sample population ascertainment}

134 The couples included in this study were selected from PGD cycles performed in our referring 135 facilities from January 2007 to August 2008. Centers referring these cycles were asked to 136 provide information on the first (AMA, RPL, etc.) and second indication (gender selection) for 137 PGD, and if gender selection was mentioned, race and gender desired was recorded.

138 Those confirmed to have requested gender determination were classified according to reason for 139 the request, including X-linked diseases, family balance, gender bias, or unknown; and classified 140 by ethnicity into Chinese, Indian, Middle Eastern and Western (Caucasian, Hispanic and 141 African-American).

142 Statistical comparisons between groups were made using Chi-square and Fisher's exact test, with 143 a level of significance of $\mathrm{P}<0.05$ (GraphPad InStat 3). 


\section{Biopsy, fixation and FISH}

146 Embryos were biopsied on day 3 of development by removing a single blastomere, followed by 147 nuclear fixation using the slightly modified Carnoy method (Velilla et al., 2002). The fixed cells

148 were sent to Reprogenetics laboratories either at Livingston, NJ or South San Francisco, CA, for

149 FISH analysis, and results were provided on days 3 to 5 of embryo development.

150 PGD was performed by FISH as part of the analysis of 5 (X, Y, 13, 18, 21), 9 (X, Y, 13, 15, 16,

$15117,18,21,22)$ or 12 chromosomes (X, Y, 8, 13, 14, 15, 16, 17, 18, 20, 21, 22) as previously

152 reported (Munné et al., 1998a; Colls et al., 2007). In cycles analyzing 9 and 12 chromosomes,

153 chromosomes X and Y were analyzed by using probes [CEP X, DXZ1 within Xp11.1-q11.1] and

154 [CEP Y, DYZ1 Yq12 For cases where five chromosomes were analyzed, the FISH analysis was 155 performed by using the MultiVysion PGT panel (Abbot, Downers Grove, IL), which includes

156 the same probe for chromosome $\mathrm{X}$ used in the 9- or 12-chromosomes test and probe [CEP Y, 157 DYZ3 within Yp11.1-q11.1] for chromosome Y.

158 Our "No Result Rescue” (NRR) approach was applied after the regular FISH panels, in cases 159 where doubtful results for one or more of the analyzed chromosomes were obtained (Colls et al., 160 2007). NRR for chromosomes $X$ and $Y$ was performed by using one of these probes: [Telomeric 161 Xp22.3/Yp11.3, DXYS129], [Telomeric Xq28/Yq12, EST Cdy 16c07] or [LSI Xq12, Androgen 162 Receptor] (Abbott, Downers Grove, IL).

163 FISH signals were scored applying criteria previously described (Munné et al., 1998b)

164

165 RESULTS 
166 A total of 3,339 PGD cycles using a 5-, 9- or 12-chromosome test were reviewed. Of these, 381

167 (11.4\%) were ascertained to be for gender selection from 53 different US-based IVF centers

168 among more than 150 centers referring case material to us. Of them, 276 (72.4\%), stated the

169 preferred gender, while in the remaining 105 (27.6\%) there was no disclosure, so they could not

170 be used here.

171 Of the 276 cases included in the study, 145 (52.5\%) were referred from IVF centers located in 172 the Western half of the USA, vs. 131 (47.5\%) referred from the Eastern half of the country. The 173 reasons provided were as follows: 21/276 (7.6\%) were selecting females due to X-linked 174 diseases, 9 (3.3\%) were selecting females to potentially reduce the chances of autism, 36 (13\%) 175 were selecting females or males due to family balance, 97 (35.2\%) were selecting females or 176 males due to primary gender selection and 113 (40.9\%) were selecting females or males without 177 disclosure of the reason.

178 When we excluded the 30 cases where selection of female embryos was requested for therapeutic 179 reasons we determined that 119/246 (48.4\%) of the non-therapeutic requests were for female 180 embryos while 127/246 (51.6\%) were selecting for male embryos. However, when gender 181 preference was analyzed taking into account the reason for gender selection and ethnicity, a 182 significant bias toward male selection was seen in couples of Chinese, Indian and Arab/Muslim 183 origin compared with patients of Western origin. Results are summarized in Table 1.

184 Information regarding the gender of previous offspring was obtained in 30 cases requesting 185 gender selection for family balance, showing that 8 (26.6\%) requested family balance after 186 having one child of the opposite requested gender, 15 (50\%) after having two, 6 (20\%) after 187 having three and 1 (3.3\%) after having four. 
188 A total of 1,647 embryos were analyzed from the 246 cases of gender selection for non189 therapeutic reasons. The gender outcome of these embryos showed that there was no difference 190 in the embryo sex ratio of couples wanting either males or females. Limiting the analysis to only 191 Western couples, who are less likely to have a bias towards females, and more likely to want 192 family balance, the results showed no difference in the sex ratios regardless of the desired 193 gender. Likewise, no difference in the sex ratio was observed for normal embryos or for embryos 194 abnormal for other chromosomes. Results are summarized in Table 2.

195 In 33 cases of gender selection for non-therapeutic reasons, none of the normal embryos obtained 196 were of the desired gender. Of these, 18/33 (54.5\%) elected to have a transfer of embryos of the 197 initially undesired gender while 15 (45.5\%) decided to cancel the transfer. Regarding ethnicity, 198 in the first group, 2/18 (11.1\%) were of Indian, Chinese or Middle Eastern origin versus 6/15 (40 $199 \%$ ) in the second group.

200 Table 3 compares a series of 6977 PGD cycles for aneuploidy testing (PGD-A), with known 201 number of embryos replaced, with the cycles of PGD for gender selection (PGD-G) identified in 202 this study. Although IVF centers referring PGD cycles do not always specify the indication for 203 the test, it is obvious form this table that the vast majority of cycles in which 5 chromosomes are 204 tested or less is for the indication of gender selection.

205 It is also interesting to observe that in both groups of PGD cycles the same number of embryos 206 was replaced (1.5) (Table 3), although the number of chromosomally normal and not replaced 207 was higher in the PGD-G (2.6 embryos) than in the PGD-A group (0.8 embryos). Because the 208 average of embryos tested was actually less in the PGD-G (6.7) than in the PGD-A (8.7), the 209 difference in non-transferred normal embryos is due to the fact that more chromosome 210 abnormalities are detected with 9-12 probes tested, than with 5, and that only 5\% of PGD-A 
211 tested for 5 chromosomes compared to 58\% of PGD-G (Table 3). Indeed, on average 25\%

212 (2.2/8.7) embryos were classified as normal by PGD-A and 63\% (4.2/6.7) by PGD-G. Assuming

213 a similar rate of chromosome abnormalities in the PGD-G group, 25\% of 6.7 embryos or 1.7

214 would be normal, barely enough to replace 1.5 of them. This also means that by only testing 5

215 chromosomes in 58\% of cycles, those cycles are replacing less than 1.5 normal embryos and

216 leaving behind potential normal embryos for transfer.

217 Indeed, when only PGD-G cycles with 9-12 chromosomes tested are taken into account (Table 3)

218 the average number of normal embryos not replaced in the PGD-G group decreases from 2.6 to

219 1.6, much closer to the 0.8 embryos in PGD-A.

220

\section{DISCUSSION}

222 In contrast to poll studies that survey opinions regarding gender selection in the general 223 population, our study was designed to evaluate the choices actually made by couples who have 224 decided to gender-select through the use of PGD. Overall, the results obtained in this study

225 are in agreement with previous findings that suggest that in an ethnically diverse Western 226 society, like the United States, sex ratio cannot be disrupted by sex selection. Indeed, our data 227 showed no significant differences regarding gender preference. In the group patients of Western 228 origin, there is actually a slight but not significant preference for females. This finding 229 invalidates the unsubstantiated ethical claim, suggested by some, that sex selection is always a 230 sexist procedure favoring males (United Nations 1995; ACOG 2007; Hanson et al., 2002; 231 Shenfield 2005).

232 However, a significant deviation towards preference for males was observed in patients of 233 Chinese, Indian and Middle Eastern/Muslim ethnicity. Similar results were obtained by Gleicher 
234 and Barad (2007) also in the analysis of a series of PGD cases for sex selection in the New York

235 area, showing a strong preference for males in the same ethnic subpopulations, but not a

236 significant difference when the overall population is taken into account, although a slight

237 deviation towards males is described. This bias towards males in Gleicher and Barad (2007) and

238 perhaps toward females in our study may be a reflection of the ethnic composition of the group

239 of patients included in the study and thus a reflection of the geographical origin of the samples.

240 In the Gleicher and Barad study, the percentage of Chinese, Indian and Muslim patients is

241 higher, and therefore, the overall results show a slight deviation towards male. However, since

242 the patients included in our study come from 53 different IVF centers throughout the United

243 States, the ethnic composition of the patients included in this study can be considered a more

244 accurate representation of the population composition of the whole country, and therefore the

245 present results are a more accurate representation of the lack of effect of sex selection on the sex

246 ratio.

247 Dahl et al. (2006b) say that for a severe disruption in the sex ratio of a population, there must be

248 a strong preference for a specific gender and at the same time there must be a high demand of

249 assisted reproductive technology with PGD for sex selection. We can agree with the former but

250 simple observation shows the latter need not be present. In China, where the population control

251 laws of the late 1970s require not more than one child per family, a strong preference for males

252 has led to abortion and infanticide of female newborns, creating an excess of males. Chinese

253 society has long fiercely discriminated against females, just as is often the case in Hindu and

254 Muslim societies. The results of male bias mean many males will not find wives, and -- in theory

255 -- that females at last have a choice of suitors. Few women in this situation will accept forcibly

256 arranged marriages or discriminatory mistreatment when multiple choices of husband are 
257 available. There are many examples in the natural world, particularly among herbivores, (Fisher 258 1930; Maynard Smith 1980) and in the human history (Trivers 1985; Sureau 1999) that echo this 259 situation. It is our opinion, therefore, that in the longer term, an excess of males in a society will 260 have two obvious effects: one, that discriminatory behavior against females will diminish and 261 eventually disappear; and two, any continued activities for direct sex selection will change to 262 return the sex ratio to equilibrium. Thus an unbalanced sex ratio can only be self-correcting in 263 the longer term.

264 However, in the ethnically diverse United States there is no overall preference for any particular 265 gender when PGD for sex selection is requested, with the exception of some ethnic populations, 266 which represent an extremely small percentage of the US population (Chinese $0.9 \%$, Indian 267 0.6\%) (U.S. Census Bureau 2000). Neither does the United States have a high demand for 268 assisted reproductive technology with PGD for sex selection, since only a small fraction of the 269 total population does request PGD, and of those, only 11.4\% also request gender selection.

270 In our study only $10.9 \%$ of the cases referred for sex selection were for a medical reason, usually

271 for female embryos because of X-linked diseases or to decrease the chance of autism which 272 primarily affects males (Yeargin-Allsopp et al., 2003; Chakrabarti and Fombonne, 2005).

273 Then there is the popular belief that some couples with multiple children of the same gender 274 must have been predisposed in this direction. To assess the validity of this belief, a 1997 study 275 of all 549,048 births in Scotland over a 14 year period, looked at the gender of fourth and fifth 276 newborns from families in which all previous children were of one gender or the other 277 (Maconochie and Roman, 1997). If gender predisposition is a real phenomenon, the gender of 278 the later-born children should be skewed toward the gender of their older siblings. But the data 279 failed to support this hypothesis. 
280 Our study extended these findings by considering the gender ratio of embryos produced by

281 couples who were proactive in their desire to gender-balance an unbalanced family. If there was

282 a predisposition to conceive embryos of one sex, we would expect it to show up within these

283 particular patient groups. But we found no difference in the sex ratio of their embryos, either as a

284 total or taking into account only the embryos diagnosed as 'normal', suggesting that such

285 predisposition does not exist; or, that if there is any biological selection against one gender, it did

286 not occur at this stage of development. However, since $76.6 \%$ of couples in the family balance

287 group requested gender selection after having only one or two previous children, they may not be

288 realistically considered to have a predisposition to produce embryos of a given gender, and a

289 much larger population of couples with 3 or more babies of the same sex would need to be

290 screened.

291 Based on large-scale cross-cultural statistics of newborns, it can be seen that there is a slight but

292 uniform skewing of sex ratio worldwide in favor of males with an average of 1.05 (Central

293 Intelligence Agency 2004). Different biological factors have been proposed to explain this shift

294 towards males, such as different survival rates between male and female embryos during early

295 embryo development (Crawford et al., 1987; Boklage 2005), nutritional factors (Rosenfeld and

296 Roberts, 2004; Jimenez et al., 2003; Ménézo 2006), evolutionary degeneration of the Y

297 chromosome and differential fertilization potential of X-bearing and Y-bearing sperm (Cheng et

298 al., 2007). However, the present results demonstrate that if there is any factor leading to a bias

299 towards male at the newborn stage, it does not affect the early stages of embryo development or

300 that assisted reproductive technologies neutralize that effect. It certainly does not support a better

301 fertilization potential of Y-bearing sperm (Cheng et al., 2007) at least for babies conceived 302 through ART. 
303 The fate of normal embryos that are not transferred is a difficult moral aspect of this procedure

304 for some persons. Our study showed that 54.5\% of couples undergoing gender selection PGD for

305 non-therapeutic reasons elected to have any-sex embryos available transferred when there were

306 no embryos of the desired gender; meaning that $45.5 \%$ chose to discard. Taken into account that

307 only $13.4 \%$ of the PGD-G failed to produce normal embryos of the desired gender, $6.1 \%$ of all

308 cycles had no transfer due to lack of normal embryos of the preferred gender.

309 In those cases were no embryos were replaced there was a significant deviation towards Indian,

310 Chinese and Middle Eastern origin (40\%) versus the $11.1 \%$ found in the group that elected to

311 have embryos transferred even when not the desired gender, which is a natural reflection of those

312 cultural backgrounds.

313 One can argue that in addition to this $6.1 \%$ of cycles with no transfer, many other normal

314 embryos are not replaced because of gender in cycles with transfer. However Table 3 shows that

315 the same average number of embryos is replaced (1.5 embryos) in PGD-A and PGD-G cycles.

316 Extrapolating the number of abnormalities seen in PGD-A (75\%) to PGD-G, the number of

317 normal embryos not replaced would be actually less than in PGD-A. In PGD-A the residual

318 number of normal embryos not replaced are usually those of poor morphology since on average

$319<2 \%$ of cycles with PGD-A produce frozen embryos. Thus, apparently PGD-G does not increase

320 significantly the number of non-replaced embryos, but this is misleading. For those PGD-G

321 cycles in which only 5 chromosomes were tested, less detection of chromosome abnormalities

322 means that less normal embryos were replaced in total. Thus, to have a less controversial PGD-G

323 program one should test for as many chromosome abnormalities as possible, furthermore when

324 now it is known that embryo biopsy produces a slight to significant detrimental impact on

325 implantation, depending on the biopsier and cells biopsied (Cohen et al. 2007, Goessens et al. 
326 2008, Munne et al. 2007), thus, if the biopsy is to be done, it should confer the maximum

327 selection and thus maximum advantage to that cycle. Testing more chromosomes in PGD-G

328 would prevent that less normal embryos are left non-replaced, since couples may decide to

329 replace those of another gender if non of the desired gender are found, and this possibility will

330 increase with more chromosomes tested. In addition, by testing more chromosomes after the

331 same biopsy, more normal embryos in general will be replaced, and thus the pregnancy outcome

332 should increase. This should be further analyzed with a large dataset.

334 To conclude, this study demonstrates that sex selection by PGD in an ethnically diverse Western 335 society, like the United States, does not have any significant effect on population sex ratio, does 336 not discriminate against female embryos, and seldom results (6\%) in the non replacement of any 337 normal embryos because such embryos were not of the desired gender, provided that the PGD-G 338 test analyzes as many chromosomes as possible. Since these are the main concerns that ethics 339 committees and scientific societies from Western countries raise in support of their opposition to 340 gender selection by PGD, it seems clear that Western objections to gender selection are not well-

341 founded. Furthermore, the alternative to PGD or sperm selection for gender in some Asian 342 countries is infanticide, which is universally repugnant. Thus, for those couples who desire 343 gender selection, earlier methods are clearly preferable. We believe that it is incumbent upon 344 committees and scientific societies who have formulated policy statements on gender selection to 345 start anew with the actual facts in the pursuit of rational policymaking that protects private 346 interests when those interests bear no negative consequences for society at-large. 


\section{REFERENCES}

350

351 American College of Obstetricians and Gynecologists, Committee of Ethics 2007 ACOG

352 Committee Opinion (Number 360). Obstetrics Gynecology 109, 475-478.

353

354 Amor DJ, Cameron C 2008 PGD gender selection for non-Mendelian disorders with unequal sex

355 incidence. Human Reproduction 23, 729-734.

356

357 Boklage CE 2005 The epigenetic environment: secondary sex ratio depends on differential 358 survival in embryogenesis. Human Reproduction 20, 583-587.

360 Chakrabarti S, Fombonne E 2005 Pervasive developmental disorders in preschool children: 361 confirmation of high prevalence. American Journal of Psychiatry 162, 1133-1141.

362

363 Cheng H, Shang X, He Y, Zhang T, Zhang Y, Zhou R 2007 Insight into human sex ratio 364 imbalance: the more boys born, the more infertile men. Reproductive Biomedicine Online 15, 365 487-494.

366

367 Central Intelligence Agency 2004 The World Factbook 2004

368 www.cia.gov/cia/publications/factbook 
370 Cohen J, Wells D, Munné S (2007) Removal of two cells from cleavage stage embryos is likely

371 to reduce the efficacy of chromosomal tests employed to enhance implantation rates. Fertil Steril,

$372 \quad 87: 496-503$

373

374 Colls P, Escudero T, Cekleniak N, Sadowy S, Cohen J, Munné S 2007 Increased efficiency of 375 preimplantation genetic diagnosis for infertility using "no result rescue”. Fertility and Sterility $376 \quad \mathbf{8 8}, 53-61$.

377

378 Crawford MA, Doyle W, Meadows N 1987 Gender differences at birth and differences in fetal 379 growth. Human Reproduction 2, 517-520.

380

381 Dahl E, Beutel M, Brosig B, Hinsch KD 2003 Preconception sex selection for non-medical 382 reasons: a representative survey from Germany. Human Reproduction 18, 2231-2234.

383

384 Dahl E, Beutel M, Brosig B, Grussner S, Stobe-Richeter Y, Tinneberg HR, Brahler E 2006a

385 Social sex selection and the balance of the sexes: empirical evidence from Germany, the UK and 386 the US. Journal Assisted Reproduction Genetics 23, 311-318.

388 Dahl E, Gupta RS, Beutel M, Stoebel-Richter Y, Brosig B, Tinneberg HR, Jain T 2006b

389 Preconception sex selection demands and preferences in the United States. Fertility and Sterility

$390 \quad 85,468-473$.

391 
392 Escudero T, Estop A, Fischer J, Munné S 2008 Preimplantation genetic diagnosis for complex

393 chromosome rearrangements. American Journal of Medical Genetics 146, 1662-1669.

394

395 Ethics Committee of the American Society for Reproductive Medicine 2001 Preconception 396 gender selection for non medical reasons. Fertility and Sterility 75, 861-864.

398 Fejes I, Szollosi J, Zavaczki Z, Koloszar S, Pal A 2006 A boy or a girl? A Hungarian survey 399 regarding gender selection. Acta Obstetrica Gynecologica Scandinavia 85, 993-996.

400

401 Fiorentino F, Magli MC, Podini D, Ferraretti AP, Nuccitelli A, Vitale N, Baldi M, Gianaroli L 4022003 The minisequencing method: an alternative strategy for preimplantation genetic diagnosis 403 of single gene disorders. Molecular Human Reproduction 9, 399-410.

405 Fisher RA 1930 The genetic Theory of Natural Selection. Clarendon Press, Oxford.

407 Garrisi JG, Colls P, Ferry KM, Zheng X, Garrisi MG, Munné S 2008 Effect of infertility, 408 maternal age, and number of previous miscarriages on the outcome of preimplantation genetic 409 diagnosis for idiopathic recurrent pregnancy loss. Fertility and Sterility Epub ahead of print.

411 Gianaroli L, Magli MC, Ferraretti AP, Munné S 1999 Preimplantation diagnosis for aneuploidies 412 in patients undergoing in vitro fertilization with a poor prognosis: identification of the categories 413 for which it should be proposed. Fertility and Sterility 72, 837-844. 
415 Gleicher N, Barad DH 2007 The choice of gender: is elective gender selection, indeed, sexist?

416 Human Reproduction 22, 3038-3041.

417

418 Goossens V, De Rycke M, De Vos A, Staessen C, Michiels A, Verpoest W, Van Steirteghem A, 419 Bertrand C, Liebaers I, Devroey P, Sermon K (2008) Diagnostic efficiency, embryonic 420 development and clinical outcome after the biopsy of one or two blastomeres for Preimplantation 421 genetic diagnosis. Human Reprod, 23:481-492

422

423 Hanson C, Hamburger L, Janson PO 2002 Is any form of gender selection ethical? Journal 424 Assisted Reproduction Genetics 19, 431-432.

425

426 Harper JC, Wells D, Piyamongkol W, Abou-Sleiman P, Apessos A, Ioulianos A, Davis M, Doshi

427 A, Serhal P, Ranieri M, Rodeck C, Delhanty JD 2002 Preimplantation genetic diagnosis for

428 single gene disorders: experience with five single gene disorders. Prenatal Diagnosis 22, 525-

429533.

430

431 Heyd D 2003 Male or female, we will create them: the ethics of sex selection for non-medical 432 reasons. Ethical Perspectives 10, 204-214.

433

434 Human Fertilization and Embryology Authority 2003 Code of Practice, $6^{\text {th }}$ edition. London:

435 HEFA.

436 
437 International Federation of Gynecology and Obstetrics (FIGO). Committee for the Ethical

438 Aspects of Human Reproduction and Women’s Health 2006 Ethical guidelines on sex selection

439 for non-medical purposes. International Journal Gynaecology Obstetrics 92, 329-330.

440

441 Jain T, Missmer SA, Gupta RS, Hornstein MD 2005 Preimplantation sex selection demand and

442 preference in an infertile population. Fertility and Sterility 83, 649-658.

443

444 Jimenez A, Madrid-Bury N, Fernandez R, Perez-Garnelo S, Moreira P, Pintado B, De la Fuente

445 J, Gutierrez-Adan A 2003 Hyperglicemia-induced apoptosis affects sex ratio of bovine and

446 murine preimplantation embryos. Molecular Reproduction and Development 65, 180-187.

448 Maconochie N, Roman E 1997 Sex ratios: are there natural variations within the human

449 population?. British Journal of Obstetrics and Gynecology 104, 1050-1053.

450

451 Maynard Smith J 1980 A new theory of sexual investment. Behaviour Ecology Sociobiology 7, $452 \quad 247-251$.

453

454 Ménézo YJ 2006 Paternal and maternal factors in preimplantation embryogenesis: interaction 455 with the biochemical environment. Reproductive Biomedicine Online 12, 616-621.

457 Munné S, Magli C, Bahce M, Fung J, Legator M, Morrison L, Cohen J, Gianaroli L 1998a 458 Preimplantation diagnosis of the aneuploidies most commonly found in spontaneous abortions 459 and live births: XY, 13, 14, 15, 16, 18, 21, 22. Prenatal Diagnosis 18, 1459-1466. 
461 Munné S, Marquez C, Magli C, Morton P, Morrison L 1998b Scoring criteria for preimplantation 462 genetic diagnosis of numerical abnormalities for chromosomes X, Y, 13, 16, 18 and 21. 463 Molecular Human Reproduction 4, 863-70.

464

465 Munné S, Magli MC, Cohen J, Morton P, Sadowy S, Gianaroli L, Tucker M, Márquez C, Sable 466 D, Ferraretti AP, Massey JB, Scott R 1999 Positive outcome after preimplantation diagnosis of 467 aneuploidy in human embryos. Human Reproduction 14, 2191-2199.

468

469 Munné S, Sandalinas M, Escudero T, Velilla E, Walmsley R, Sadowy S, Cohen J, Sable D 2003

470 Improved implantation after preimplantation genetic diagnosis of aneuploidy. Reproductive

$471 \quad$ Biomedicine Online 7, 91-97.

472

473 Munné S, Chen S, Fischer J, Colls P, Zheng X, Stevens J, Escudero T, Oter M, Schoolcraft B, 474 Simpson JL, Cohen J 2005 Preimplantation genetic diagnosis reduces pregnancy loss in women 475 aged 35 years and older with a history of recurrent miscarriages. Fertility and Sterility 84, 331476335.

477

478 Munné S, Gianaroli L, Tur-Kaspa I, Magli C, Sandalinas M, Grifo J, Cram D, Kahraman S, 479 Verlinsky Y, Simpson JL 2007. Sub-standard application of PGS may interfere with its clinical $480 \quad$ success. Fertil Steril, 88:781-784 
482 Otani T, Roche M, Mizuike M, Colls P, Escudero T, Munné S 2006 Preimplantation genetic

483 diagnosis significantly improves the pregnancy outcome of translocation carriers with a history

484 of recurrent miscarriage and unsuccessful pregnancies. Reproductive Biomedicine Online 13,

$485 \quad 869-874$.

486

487 Robertson JA 2002 Sex selection for gender variety by preimplantation genetic diagnosis.

$488 \quad$ Fertility and Sterility 78, 463.

489

490 Rosenfeld CS, Roberts RM 2004 Maternal diet and other factors affecting offspring sex ratio: a

491 review. Biology of Reproduction 71, 1063-1070.

492

493 Shenfield F 2005 Procreative liberty, or collective responsibility? Comment on the House of

494 Commons report Human Reproductive Technology and the Law, and on Dahl's response.

495 Reproductive Biomedicine Online 11, 155-157.

496

497 Sureau C 1999 Gender selection: a crime against humanity or the exercise of a fundamental 498 right? Human Reproduction 14, 867-868.

499

500 Trivers R 1985 Social Evolution. Benjamin-Cummings, Menlo Park, California

501 United Nations 1995 Gender equality, equity and empowerment of women. Population and

502 Development: Programme of Action Adopted at the International Conference on Population and

503 Development, 5-13 September 1994. Cairo, New York. UN, 17-21.

504 
505 United States Census Bureau 2000 Profiles of General Demographic Characteristics. 2000

506 Census of Population and Housing. http://www.census.gov/prod/cen2000/dp1/2kh00.pdf

507

508 Velilla E, Escudero T, Munné S 2002 Blastomere fixation techniques and risk of misdiagnosis

509 for preimplantation genetic diagnosis of aneuploidy. Reproductive BioMedicine Online 4, 210510217.

511

512 Yeargin-Allsopp M, Rice C, Karapurkar T, Doernberg N, Boyle C, Murphy C 2003 Prevalence

513 of autism in a US metropolitan area. The Journal of the American Medical Association 289, 49-

51455.

515

516

517

518

519

520

521

522

523

524 Table 1. Gender preference by reason and ethnicity.

525

526

Reasol

Ethnicity Cases

Male

Female

significance

527
Family balance

Middle East

1

$1(100 \%)$

$0(0 \%)$ 
528

529

530

531

532

533

534

535

536

537

538

539

540

541

542

543

544

545 Total

546

547

548

549

550

\begin{abstract}
Chinese
\end{abstract}
Indian

Total

Western

23
$1(50 \%) \quad 1(50 \%)$

$10(100 \%) \quad 0(0 \%)$

$12(92.3 \%) \quad 1(7.7 \%)$

$\mathrm{P}<0.05$

$12(52.2 \%) \quad 11(47.8 \%) \quad \mathrm{P}=1.0000$

\section{Primary selection Middle East 8}

Chinese $\quad 6$

Indian

Total

Western

12

26

71

Middle East $\quad 8$

Chinese $\quad 7$

Indian

Total

Western

90

8

23

8

$6(75 \%) \quad 2(25 \%)$

4 (66.6\%) $\quad 2(33.3 \%)$

9 (75\%) $3(25 \%)$

19 (73.1\%) $\quad 7(26.9 \%) \quad \mathrm{P}=0.1534$

$21(29.6 \%) \quad 50(70.4 \%) \quad \mathrm{P}=0.0252$ 
551 
552 Table 2. Gender outcome of analyzed embryos from different groups of patients.

553

554 Patient

Total Total

Normal

Normal

555 Group

Male

Female

Male

Female

556

557 Total patients

$784(47.6 \%) \quad 863$ (52.4\%)

507 (49.6\%)

515 (50.4\%)

558 Select Male

418 (49.2\%)

$432(50.8 \%)$

278 (50.9\%)

$268(49.1 \%)$

559 Select Female

$366(45.9 \%)$

431 (54.1\%)

$229(48.1 \%)$

247 (51.9\%)

560

561 Western patients

$581(47.1 \%)$

$653(52.9 \%)$

$361(48.6 \%)$

381 (51.4\%)

562 Select Male

$251(49.4 \%)$

257 (50.6\%)

158 (50.6\%)

$154(49.4 \%)$

563 Select Female

$330(45.4 \%)$

396 (54.6\%)

$203(47.2 \%)$

227 (52.8\%)

564

565

Family balancing

89 (50.6\%)

87 (49.4\%)

$60(52.6 \%)$

$54(47.4 \%)$

566 Select Male

58 (49.6\%)

59 (50.4\%)

$36(52.2 \%)$

$33(47.8 \%)$

567 Select Female

$31(52.5 \%) \quad 28$ (47.5\%)

$24(53.3 \%)$

$21(46.7 \%)$

568

569

570

571

572

573 
574 Table 3: Comparison of PGD cycles of aneuploidy and gender selection

575

576

PGD for aneuploidy PGD for gender selection

577 \# Av.

$\#$

Av.

$578 \quad$ Age $<35$

579 cycles

1867

85

580 av. Age

31.1

31.1

581 \# embryos tested

$19548 \quad 10.5$

$610 \quad 7.2$

582 \# embryos normal

$6497 \quad 3.5$

$423 \quad 5.0$

583 \# embryos replaced

3456

1.9

119

1.4

584 Av. Normal non replaced

1.6

3.6

585 cycles with 5 chromosomes tested*

$150.0 \quad 8.0 \%$

61

$71.8 \%$

586

$587 \quad$ age $35-39$

588 cycles

2321

75

589 av. Age

37.2

36.9

590 \# embryos tested

$20314 \quad 8.8$

467

6.2

591 \# embryos normal

$5452 \quad 2.3$

245

3.3

592 \# embryos replaced

3783

1.6

$113 \quad 1.5$

593 Av. Normal non replaced

0.7

1.8

594 cycles with 5 chromosomes tested*

108

$4.7 \%$

41

$54.7 \%$

595

$596 \quad$ age $>39$ 


$\begin{array}{llcccc}597 & \text { cycles } & 2789 & & 86 & \\ 598 & \text { av. Age } & 43.5 & & 44.1 & \\ 599 & \text { \# embryos tested } & 20947 & 7.5 & 570 & 6.6 \\ 600 & \text { \# embryos normal } & 3589 & 1.3 & 354 & 4.1 \\ 601 & \text { \# embryos replaced } & 2941 & 1.1 & 139 & 1.6 \\ 602 & \text { Av. Normal non replaced } & & 0.2 & 2.5 & \\ 603 & \text { cycles with 5 chromosomes tested* } & 102 & 3.7 \% & 40 & 46.5 \%\end{array}$

604

605

606 Total cycles with 9-12 chromosomes tested

607 cycles

6617

104

608 av. Age

38

38.5

609 \# embryos tested

$58167 \quad 8.8$

$703 \quad 6.8$

610 \# embryos normal

$14477 \quad 2.2$

$306 \quad 2.9$

611 \# embryos replaced

9600

1.4

138

1.3

612 Av. Normal non replaced

0.8

1.6

613

\section{Total}

615 cycles

6977

246

616 av. Age

38.1

37.4

617 \# embryos tested

$60809 \quad 8.7$

1647

6.7

618 \# embryos normal

$15538 \quad 2.2$

1022

4.2

619 \# embryos replaced

$10180 \quad 1.5$

371

1.5 
620 Av. Normal non replaced

0.8

2.6

621

cycles with 5 chromosomes tested*

360

$5.2 \%$

142

$57.7 \%$

622

623

$624 *$ The rest of cycles had 9 to 12 chromosomes tested 